\title{
A Practical Approach to Fabric-Formed Concrete
}

\author{
Kaloyana Kostova ${ }^{1}$, Tim Ibell ${ }^{2}$, Antony Darby ${ }^{2}$, and Mark Evernden ${ }^{2}$ \\ ${ }^{1}$ Tony Gee and Partners, 301 Stonehouse Park, Stonehouse, UK. E-mail: \\ kaloyana.kostova@tonygee.com \\ ${ }^{2}$ University of Bath, Claverton Down, Bath, UK. E-mail: <t.j.ibell@bath.ac.uk>, \\ <a.p.darby@bath.ac.uk>,<m.evernden@bath.ac.uk>.
}

\begin{abstract}
Fabric formwork holds huge potential to offer an economically viable alternative to conventional rigid moulds by casting concrete in flexible membranes, which are allowed to deflect and create non-uniform concrete shapes. However, the complexity of design and the uncertainty in achieving adequate construction tolerances present major challenges to the application of fabric-formed concrete for building structural elements. This paper proposes a practical approach to form-finding and design of structural concrete elements cast in fabric formwork, readily applicable in conjunction with conventional design methods. It also provides guidance on the control of dimension tolerances during construction and encourages consideration of new possibilities for a combination of fabric formwork and flexible reinforcement types in the future.
\end{abstract}

Keywords: Fabric-formed concrete, formwork, rigid moulds.

\section{INTRODUCTION}

Shaping concrete elements appropriately in order to use the concrete material more efficiently may not be a new idea but still has limited application due to the complexity of building suitable concrete moulds. Flexible formwork systems such as fabric formwork can change fundamentally the design practice and the appearance of concrete structures due to the immense possibilities for creativity and close work between architects and engineers in designing forms that are both architectural in intent and structurally efficient. This approach holds sustainability-driven advantages which should be exploited.

Patents from the past reveal an early development of flexible formwork methods using woven vegetable fabric or even paper to cast concrete slabs with curved soffits, columns, walls and shells (Lilienthal, 1899; Waller, 1934). However, such inventions remained mostly unknown and separated in time, which could be related to the lack of suitable fabric material before the age of large-scale industrial production of synthetic fibres in the 1960s, when a range of high-strength fabrics, including polyester, polyamide, polypropylene and polyethylene, became economically viable for fabric 
formwork applications, such as beach protection concrete mattresses, jacketing of bearing piles under water, encasement of underwater structures and pipelines, as well as repairs of underwater structures (Lamberton, 1989). These methods have been further developed and have become widely used in marine construction (Hawkswood, 2012), while the opportunity to cast aesthetical concrete elements has been explored mainly by architects and researchers who recognised the potential of the technique and the challenges that need to addressed in order to make fabric-formed concrete an available option to practising designers.

There are many examples of fabric-formed elements and structures built around the world over the last decades, with the majority of the tested methods for construction being developed and described in detail by West (2016), which also demonstrates the advantages of fabric formwork over conventional systems. An example of a building composed of fabric-formed walls is shown in Figure 1. The key advantages may be found in the simplicity of fabric formwork as a low technological and accessible construction method, and in the characteristics of fabric as a lightweight and re-usable material. These advantages also apply over the emerging 3-D printing technologies in construction.

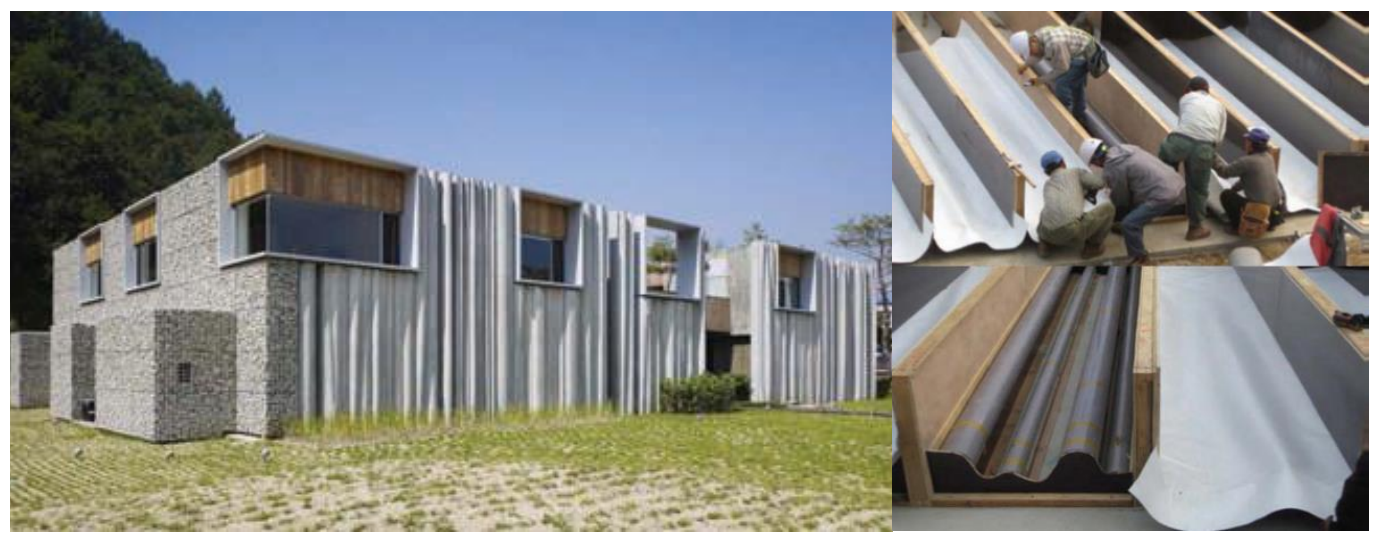

Fig. 1. Fabric formwork construction (Courtesy of Mark West)

The present paper aims to propose a practical approach to the design and construction of fabric-formed structural concrete elements. It provides a valuable insight into the achievable construction tolerances and buildability of such elements, based on experimental and analytical studies. Finally, it offers the possibility to produce selfforming reinforced concrete elements with variable geometry without the need to predeform steel bars.

\section{RESEARCH PROBLEM AND SIGNIFICANCE}

The capability to design and build fabric-formed concrete structures expands beyond common design practice due to the complex interaction between the process and material, identified by Manelius (2012) as stereogeneous architecture, in which the final form reveals traces of the construction process. From the design perspective, this 
requires additional effort in predicting the deformed shape of fabric filled with wet concrete, which defines the final outline of hardened concrete. In order to ensure that the final form will also be structurally efficient, an optimisation process must be integrated, transforming a simple design check into a complex iterative procedure. There are methods available for form-finding and structural optimisation, which can be adapted to solve the problem, however they require clearly defined objectives and constraints, determined by the construction process. Therefore, the key problem is how design and construction could be merged, as well as to allow the construction to evolve and feed back into the design through exploration of the physical boundaries and learning from experimental construction.

Building the desired shapes within the limits of standard construction tolerances is the next critical question, which requires the development of appropriate construction techniques to eliminate the apparent risk of not matching a flexibly-formed concrete profile with a pre-deformed steel reinforcement profile. A logical step in the research of fabric formwork is also the realisation of the intrinsic similarity between synthetic fibre fabrics and the Fibre-Reinforced Polymer (FRP) materials, which could be utilised as reinforcement in concrete structures. Both materials are lightweight and flexible. Glass FRP bars permit field forming of large radius curves, which suggests a possible new application of fabric formwork as a means of forming reinforcement profiles under the natural self-weight force of wet concrete.

The presented research attempts to answer these questions by proposing a simplified method for form-finding and optimisation suitable for conventional sectional analysis of reinforced concrete elements, which has been verified through experimental studies, in order to provide a practical tool and guidance on the construction possibilities to designers. The significance of the research is that it allows architects and engineers to further engage and explore the application of fabric formwork for architectural and structural forms.

\section{FORM-FINDING AND DESIGN}

\section{Form-Finding Methods}

The form-finding process involves determining the deformed shape of fabric under the hydrostatic pressure exerted by wet concrete and can be related to the form-finding of pre-tensioned membrane structures. However, there are distinct differences between fabric-formed and tensioned membrane structures, which require further research in order to adapt available methods. The differences may arise from the influence of the setting of concrete during construction, the bleeding of excessive water through permeable fabrics, the influence of 'pinch' points and the allowance for wrinkling not typical for minimal surface form-finding of pre-tensioned membranes (Veenedaal et al., 2011).

A novel form-finding approach based on the force density method was developed by Van Mele and Block (2010) for the design of thin anticlastic concrete shells built in flexible formwork. Similarly, Tysmans et al. (2011) proposed a form-finding 
methodology for the design of anticlastic shell shapes made of fire-safe textile reinforced cement composite, based on dynamic relaxation with kinetic damping. Topology optimisation, based on the BESO algorithm was used by Bak et al. (2012) to first determine the design concrete shape and then 'drape' fabric 'over the optimised shape by using a detecting collision approach. Other techniques include evolutionary optimisation algorithms combined with structural analysis in ANSYS (Veenedaal, 2008).

Several studies at the University of Bath focused on the development of a simplified 2-D form-finding method, compatible with sectional analysis and structural optimisation of reinforced concrete cross sections. The form-finding approach progressed from experimentally obtained empirical relations for the top breadth, depth and perimeter of sections horizontally cast in a freely hung fabric membrane (Bailiss, 2006; Garbett, 2008) to a numerical solution describing the full concrete outline for known top breadth and depth of a cross section (Foster and Ibell, 2016). The procedure was further developed to allow for analysis of sections with various forms of restraints controlling the geometry during construction (Kostova, 2016).

\section{Evolution of Construction Methods}

Structural optimisation techniques indicate where the concrete material is needed; however, they could remain limited by the physical shape which fabric can assume during construction unless external shape formers are used to avoid undesired deflection of fabric, adding significant complexity to the construction process, which may counter the key advantages of fabric formwork.

While studying the feasibility of applying the bone-growth analogy to fabric-formed concrete beams, Garbett (2008) demonstrated that sandwiching freely hung fabric between stiff web formers could result in producing highly efficient structurally 'keyhole' shaped cross sections. The experimental part of the study was less successful as the web formers were propped independently of the fabric, which proved difficult to control during construction, suggesting that external restraints might impair the buildability of fabric-formed concrete elements.

Alternative methods for reducing unnecessary bulging of fabric in cross section is the use of internal restraints, similar to conventional wall formwork ties. When applied at discrete points, the ties create a waved surface resembling a mattress, a method successfully developed and promoted as a 'zero-waste' formwork system for exposed concrete walls by the Japanese architect Kenzo Unno (Umi Architectural Atelier). Figure 2a shows a close-up view of formwork ties during the different stages of construction of a mattress-type fabric-formed wall. Formwork ties can also be used to connect rigid formers through the fabric, avoiding entirely the need for external propping, as can be seen in Figure $2 \mathrm{~b}$. The internal restraints may be made of different materials than the conventional steel tie bolts. For example, plastic wire with adequate strength and stiffness could provide sufficient restraint, while it would not need to be installed in plastic tubes for ease of removal after the concrete hardens, as in the case 
of steel bolts. Figure 2c illustrates a continuous restraint of fabric achieved by tying steel rods with plastic wire through the fabric.

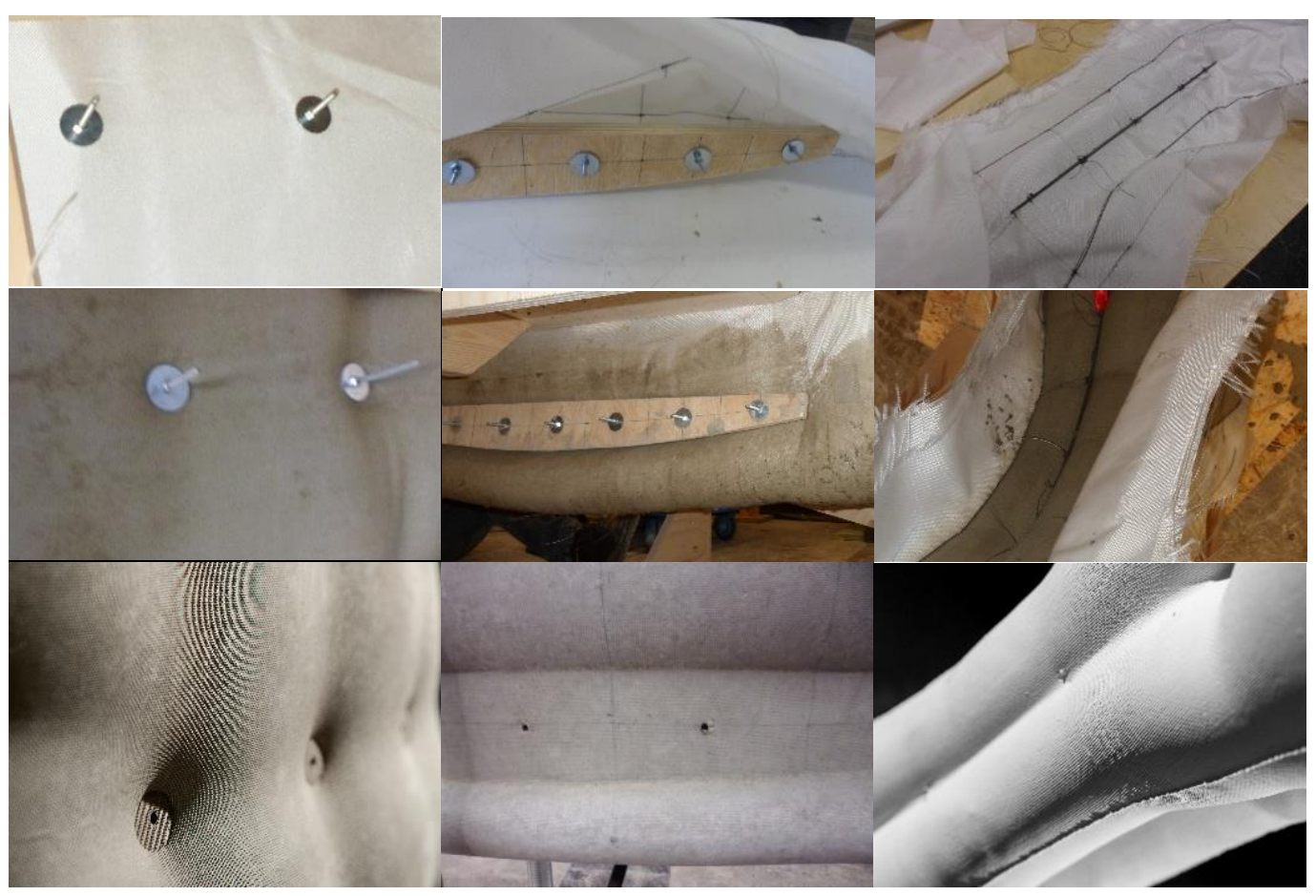
a. Discrete ties
b. Rigid web former
c. Wire-tied bar

Fig. 2. Internal restraint methods for fabric formwork construction

\section{Practical Approach to Form-Finding and Design}

Most of the described form-finding methods take into account the three-dimensional behaviour of fabric, which is imperative for the design of shell structures. However, linear structural elements, such as beams and columns, with variable geometry can be modelled and optimised by means of conventional methods as a sequence of twodimensional transverse sections. Therefore, an appropriate cross-sectional formfinding algorithm can provide a practical approach readily acceptable in current design practice.

The form-finding method developed at the University of Bath, described elsewhere (Kostova, 2016), is based on the numerical procedure proposed by Foster and Ibell (2016). The basic procedure finds the shape of a concrete cross section consisting of a single bulb, formed in a hung fabric held at its ends. For this purpose, the perimeter of the section is divided into a large number of straight lines. The relationship of the applied hydrostatic pressure, the tensile force in the fabric and the curvature of the deflected fabric is then used to express the coordinates of each straight line end, starting from the lowest point, in terms of a single unknown constant. The final outline is obtained by an appropriate goal searching algorithm for defined dimensions of the top opening breadth and the depth of the bulb (refer to the first section on the left in 
Fig. 3). Introducing internal restraints, in the form of discrete ties or vertical web formers splits the section into multiple bulbs or fixed-width webs. The initially constant force in the fabric perimeter also changes at each tie location. The refined form-finding procedure allows for the inclusion of ties by finding the relationship between the forces in each two consecutive bulbs from equilibrium in the vertical direction at the tie point. The principle can be applied to different arrangements and number of ties, some of which are illustrated in Figure 3.
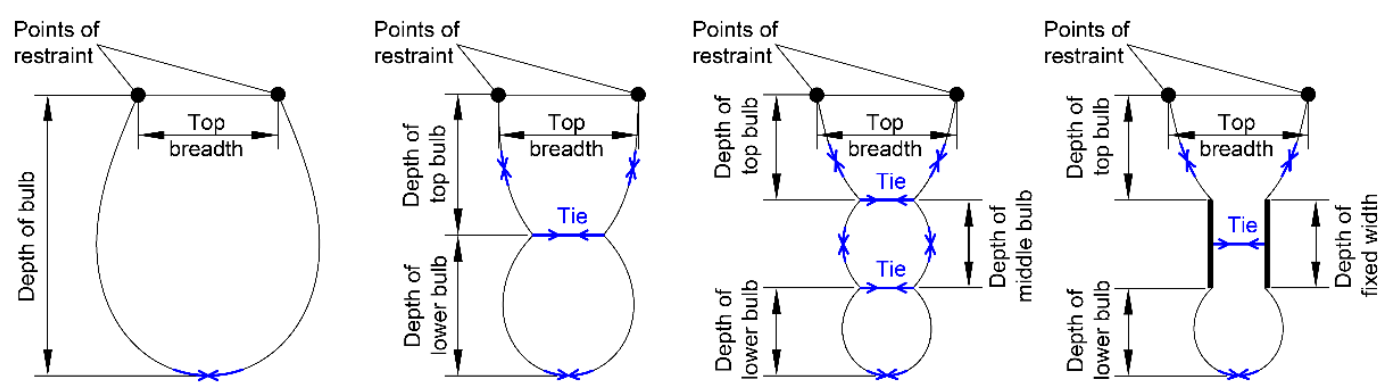

Fig. 3. Modelling fabric-formed cross sections with and without internal restraints

It is recognised that a two-dimensional form-finding method cannot provide a completely accurate representation of the three-dimensional form. However, assuming that a sufficiently large number of sections is used, three-dimensional images may be obtained by creating surfaces defined by every two adjacent cross sections. The approach is not capable of predicting wrinkling of flat fabric membranes when casting elements with large variations between adjacent cross sections. As confirmed by experimental studies (Kostova, 2016), this may only be critical for excessive variations but not for the majority of practical designs. Complex geometries are still achievable using the simplified sectional approach, if the fabric is divided into flat patterns and stitched prior to construction.

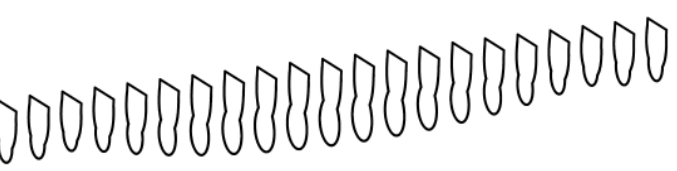
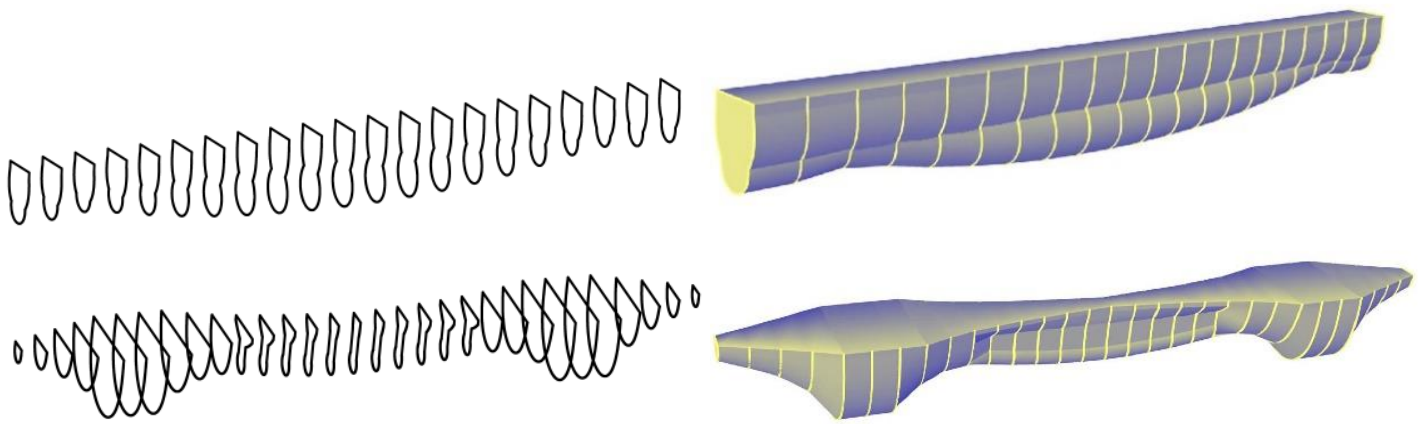

Fig. 4. 3-D visualisation of elements designed using cross-sectional form-finding 


\section{CONSTRUCTION TOLERANCES}

\section{Experimental Construction}

An experimental study was undertaken to verify the predicted geometry of fabricformed beams designed using the proposed practical form-finding approach. The beams were cast in polypropylene fabric attached to plywood sheets, supported on movable frames to allow for a large variation in the top opening (refer to Figure 5). The cross sections of each beam specimen were carefully measured with profile gauges at regular distances along the length and compared against the predicted outlines. Another method used to obtain the full geometry was laser scanning, while saw cutting of concrete was found to be the most reliable approach for determining the as-built position of reinforcing bars. The load-deflection behaviour of each beam specimen was also tested to verify theoretical predictions.
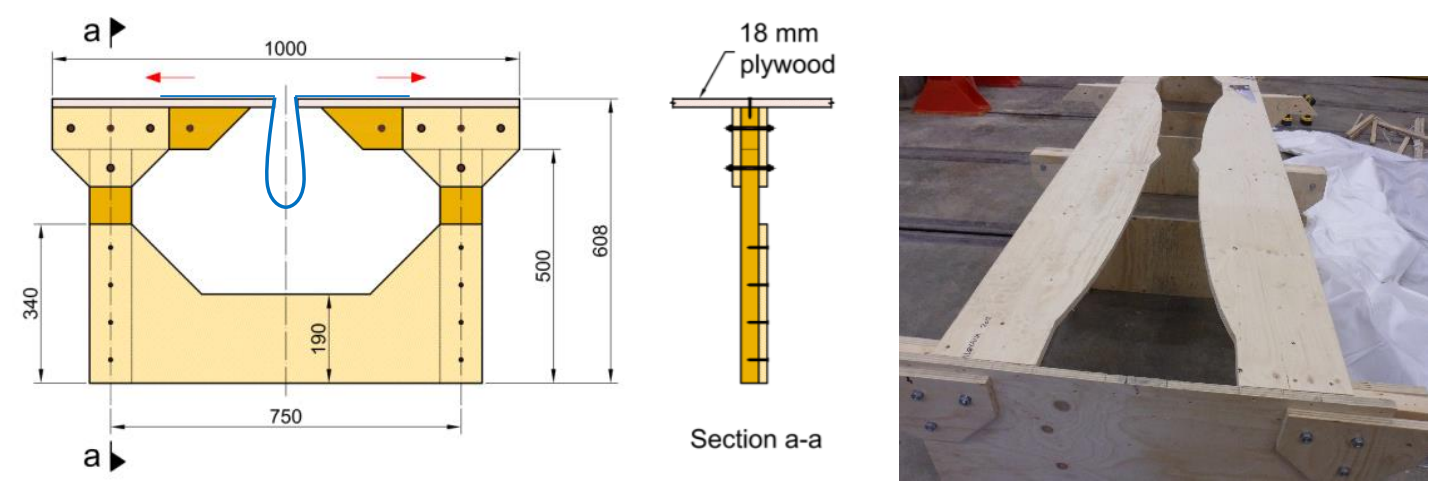

Fig. 5. Movable supporting frames allowing variation in opening

\section{Tolerance on Construction Parameters}

The construction parameters for a single bulb are the top breadth and the perimeter of the unrestrained fabric forming the bulb. In multiple-bulb sections, the tie length defines the top breadth of the lower bulb at each junction. The major implication of this is that the construction depth of a fabric-formed section is entirely controlled by the fabric perimeter, the top opening and the position and length of ties in restrained fabrics. There are no practical means of verifying the final depth prior to the casting of concrete as with conventional rigid moulds.

It is expected that the achievable tolerances on the length of the fabric perimeter would be similar to those for factory-made products. The edge support lines can be automatically printed on the fabric for ease of installation. Minor deviations from the design length would also have less effect on the final dimensions compared with the effect of variations in the top opening or tie lengths, which remain the main parameters to be controlled during construction. The plot in Figure 6, showing the nondimensional relationship of the top opening breadth and the depth of a single bulb, indicates that a change of the top breadth would not be proportional to the corresponding change in depth and would also depend on the breadth-to-depth ratio of each section. 


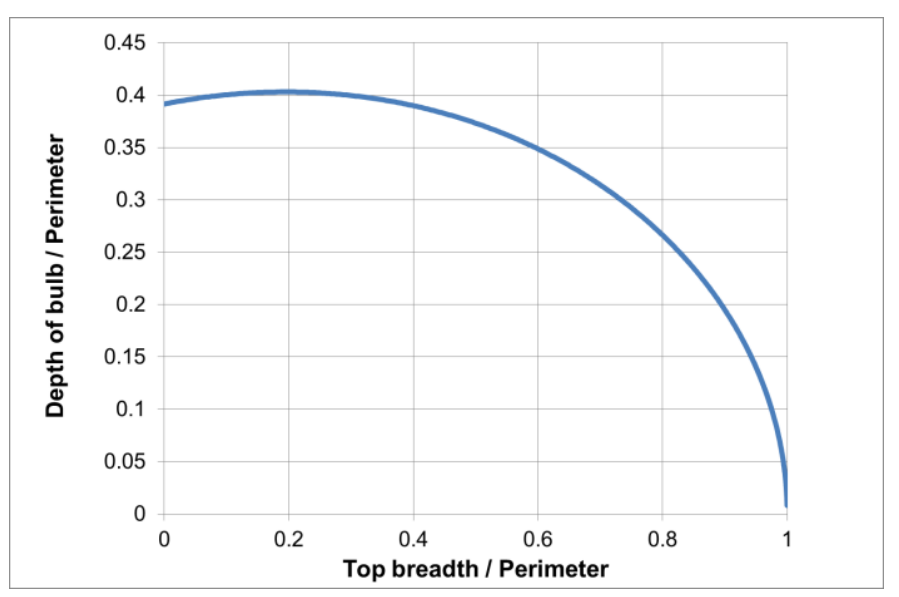

Fig. 6. Non-dimensional relationship between depth and top breadth of a bulb

As can be seen from Figure 6, the ratio of the depth-to-perimeter remains fairly constant, approximately equal to 0.4 , almost up to a breadth-to-depth ratio of 1 , suggesting that a variation in the top opening for such sections may not have a significant effect on the final depth. In contrast, for sections with large breadth-todepth ratios the curve becomes steeper indicating a greater sensitivity of the depth dimension to any variation of the top breadth. The numerical example presented in Table 1 confirms this conclusion by comparing two sections with different breadth-todepth ratios, for which the top breadth, $b$, is increased by $10 \%$. The increase causes a reduction in the final depth, $d$, assuming that the fabric perimeter, $P$, remains constant. The adjustment of the perimeter length required to maintain the original depth is also calculated in the last column. It is worth noting that for the first section a deviation of $50 \mathrm{~mm}$ would still result in less than $1 \mathrm{~mm}$ reduction in the final depth.

Table 1. Effect of construction tolerances on sections with different b/d ratio

\begin{tabular}{|l|l|l|l|l|l|l|}
\hline $\mathrm{b} / \mathrm{d}$ & $\begin{array}{l}\mathrm{b}, \\
\mathrm{mm}\end{array}$ & $\begin{array}{l}\mathrm{d}, \\
\mathrm{mm}\end{array}$ & $\begin{array}{l}\mathrm{b}+10 \%, \\
\mathrm{~mm}\end{array}$ & $\begin{array}{l}\text { Change in d, } \\
\mathrm{P}=\text { const, } \mathrm{mm}\end{array}$ & $\begin{array}{l}\text { Change in d, } \\
\mathrm{P}=\text { const \% }\end{array}$ & $\begin{array}{l}\text { Change in } \mathrm{P}, \\
\mathrm{d}=\text { const, mm }\end{array}$ \\
\hline 0.5 & 250 & 500 & 275 & 499.6 & $-0.08 \%$ & 1 \\
\hline 2 & 500 & 250 & 550 & 239.7 & $-4.11 \%$ & 32.5 \\
\hline
\end{tabular}

The two examples are further illustrated in Figure 7, where the sections are indicated on the depth-perimeter curves for specific values of the top breadth. The graph enables visual interpretation of the change in depth when the horizontal lines representing the constant perimeter of each section cross the different 'breadth' curves. A full range of depth-perimeter curves for a particular range of cross-sectional dimensions may also be useful as a practical tool to assess allowable tolerances on site and for direct reading of the required perimeter adjustment. 


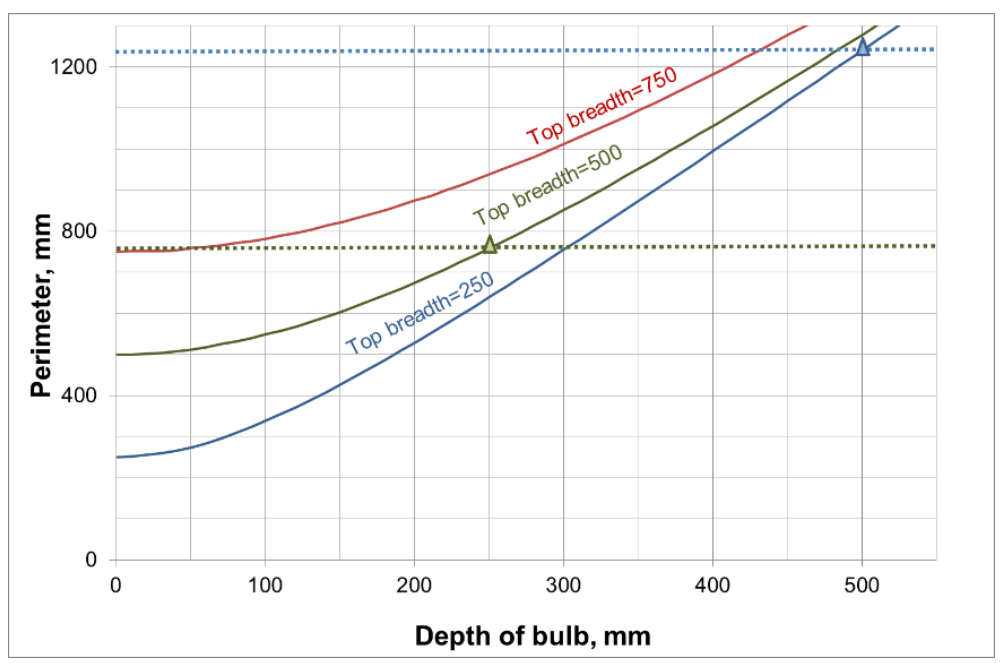

Fig. 7. Depth-perimeter curves for different top breadth dimensions

\section{SELF-FORMING REINFOCED CONCRETE BEAMS}

\section{FRP Materials for Reinforced Concrete Applications}

The fibres typically used for embedded reinforcement in concrete are made of glass due to its more affordable price compared with carbon fibre, which is more often used for externally bonded strengthening of existing structures. The strength of glass FRP composite material exceeds that of steel at a density of only $2 \mathrm{~g} / \mathrm{cm}^{3}$. The flexibility of glass FRP bars allows for field forming of large radius curves with permitted radii in the range of $1700 \mathrm{~mm}$ to $7000 \mathrm{~mm}$ for practical application, based on manufacturer's data (Aslan 100 GFRP Rebar datasheet). When attached to fabric prior to casting of concrete, the glass FRP bars are pulled down by the fabric under the self-weight of wet concrete and formed to the desired profile, without any external forces, as successfully demonstrated by the example presented in Figure 8.



Fig. 8. Glass FRP rebar tied to fabric during construction 


\section{Form Finding of Reinforcement Profiles}

If the reinforcing bars had no stiffness they would take exactly the same shape as the fabric they are attached to. In reality, they apply uplift forces, which change locally the shape of fabric in the cross section, as can be seen at the locations highlighted in Figure 8. Predicting the local uplift of fabric is very important as it would reduce the effective depth of reinforcement if not taken into account in determining the required fabric perimeter. An additional algorithm capable of predicting such profiles has been developed, based again on vertical equilibrium of forces at the tie location, and tested through construction of experimental beams. The algorithm is performed after the main optimisation process, when the final curved profile of the reinforcement is known. The uplift forces in the fabric can then be calculated from idealised beam models, as illustrated by the two examples given in Figure 9. Predicting the forces also allows checking as to whether the self-weight of the concrete is sufficient to form the desired curves.

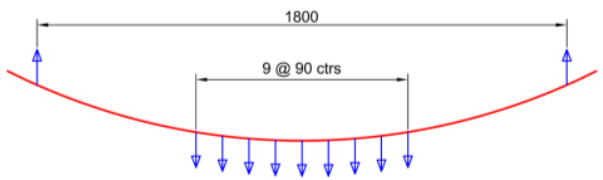

a. Curve radius $1800 \mathrm{~mm}$

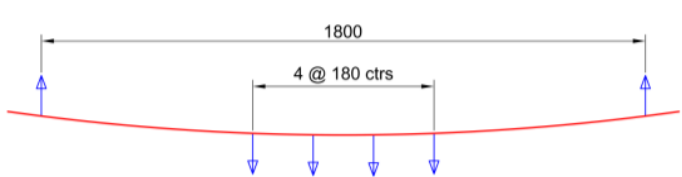

b. Curve radius $7000 \mathrm{~mm}$

Fig. 9. Idealised models for calculating uplift forces on fabric for known rebar profiles

The reinforcing bars used here had an effective diameter of $12.7 \mathrm{~mm}$ and modulus of elasticity of $69.2 \mathrm{GPa}$. Predicted uplift forces, based on the flexural stiffness of the bars were compared with calculated forces based on the actual uplift in fabric, measured after construction. The results presented in Table 2 and Table 3 show that assuming equally distributed forces in closely spaced ties could provide reasonable accuracy of results, which is further confirmed by the detailed comparison of theoretically predicted and as-built concrete profiles in Figure 10.

Table 2. Forces $[\mathrm{N}]$ in ties for reinforcing bar with curve radius $1800 \mathrm{~mm}$

\begin{tabular}{|l|l|l|l|l|l|l|l|l|l|}
\hline Predicted & 9.74 & 9.74 & 9.74 & 9.74 & 9.74 & 9.74 & 9.74 & 9.74 & 9.74 \\
\hline Actual & 10.6 & 8.73 & 9.54 & 8.73 & 9.18 & 8.55 & 9.36 & 8.73 & 10.6 \\
\hline
\end{tabular}

Table 3. Forces $[\mathrm{N}]$ in ties for reinforcing bar with curve radius $6000 \mathrm{~mm}$

\begin{tabular}{|l|l|l|l|l|}
\hline Predicted & 11.2 & 11.2 & 11.2 & 11.2 \\
\hline Actual & 11 & 11.7 & 11.7 & 11 \\
\hline
\end{tabular}




Fig. 10. Comparison of theoretically predicted and actual outlines of sections cast in fabric tied to reinforcing bars during construction

\section{CONCLUSIONS}

The design approach to fabric-formed structural concrete elements presented in this paper provides a practical solution for integrating form-finding and optimisation in the design process based on a simplified numerical procedure for form-finding the concrete outlines of cross sections along the length of a structural element. The theoretical results using this approach have been verified through an extensive experimental study. The experimental findings have also been used to provide guidance on construction tolerances and buildability of fabric-formed concrete. A novel technique for creating curved reinforcement profiles has been explored to further demonstrate the extraordinary capability of fabric formwork construction to utilise natural forces of gravity to create efficient forms. The following conclusions summarise the main points discussed in the paper:

- The design of fabric-formed concrete needs to allow for further evolution of construction methods, which is the basis of the proposed practical approach. As demonstrated, the same principles can be applied for new forms of restraint and an unlimited number of flexible or rigid ties and formers.

- Internally restrained fabric provides the most adaptable method for structurally efficient design and ease of construction.

- Cross-sectional form-finding can be used to create three-dimensional visualisation and assess the likelihood of excessive wrinkling in flat fabrics, which can be avoided by ensuring smooth transition of geometry between adjacent sections or use of flat-patterned stitched fabrics for construction.

- The effect of construction tolerances vary for different ratios of cross-sectional dimensions but can be predicted and assessed. Slight adjustments in the fabric perimeter can be done on site to improve accuracy. Use of large breadth-todepth ratios should be avoided to minimise effects of tolerances.

\section{ACKNOWLEDGEMENTS}

The authors gratefully acknowledge the financial support of the Leverhulme Trust, and the help of the technical staff in the Structures Laboratory of the Department of Architecture and Civil Engineering at the University of Bath.

\section{REFERENCES}

Aslan 100 GFRP Rebar datasheet [Online]. Available from: http://aslanfrp.com/resources/Aslan-100-GFRP-Rebar-data-sheet.pdf [Last accessed 3 March2019]. 
Bak, A., Shepherd, P. and Richens, P. (2012). "Intuitive interactive form finding of optimised fabric-cast concrete." In Proceedings of 2nd International Conference on Flexible Formwork (icff 2012), 27 - 29 June 2012, Bath, pp. 46-53.

Garbett, J. (2008). "Bone growth analogy for optimising flexibly formed concrete beams." MEng Dissertation, University of Bath.

Hawkswood, M. (2012). "Fabric Formwork Systems used in Marine Construction." In Proceedings of 2nd International Conference on Flexible Formwork (icff 2012), 27 29 June 2012, Bath, pp. 140-152.

Kostova K.Z., (2016). "Design and constructability of fabric-formed concrete elements reinforced with FRP materials." Doctoral thesis, University of Bath, Bath, UK

Lamberton, B. (1989). "Fabric forms for Concrete." Concrete International, 11 (12), pp. 59-67.

Lilienthal, L. W. G. (1899). "Fireproof ceiling." United States Patent Office patent application US619769A. 1899-02-21.

Manelius, A. (2012). "Fabric formwork for concrete: Investigations into formwork tectonics and stereogenity in architectural constructions." Doctoral Thesis. Royal Danish Academy of Fine Arts.

Umi Architectural Atelier. URC (fabric formwork) [Online]. Available from: http://www.umi-aa.com/urc-gallery/ [Last accessed 3 March2019].

Van Mele, T. and Block, P., 2010. "A novel form finding method for fabric formwork for concrete shells." In Proceedings of the International Association for Shell and Spatial Structures (IASS) Symposium 2010, 08 - 12 Nov 2010, Shanghai.

Veenendaal, D. (2008). "Evolutionary Optimization of Fabric Formed Structural Elements: Bridging the gap between computational optimization and manufacturability." Master's Thesis, Delft University of Technology.

Waller, W. (1934). "Method of building with cementitious material applied to vegetable fabrics." United States Patent Office patent application US1955716A. 193404-17.

West, M. 2016. The Fabric Formwork Book. London: Routledge, https://doi.org/10.4324/9781315675022 